\title{
VLF-EM and VES: an application to groundwater exploration in a Precambrian basement terrain SW Nigeria
}

\author{
Adebowale Obasanmi Adelusi ${ }^{1}$, Michael A. Ayuk ${ }^{1}$, John Stephen Kayode ${ }^{2, \star}$ \\ ${ }^{1}$ Federal University of Technology Akure, Department of Applied Geophysics, Akure, Nigeria \\ ${ }^{2}$ Covenant University, Department of Physics, Canaan Land, Otta, Nigeria
}

\section{Article history}

Received February 8, 2013; accepted November 22, 2013.

Subject classification:

Electromagnetic (VLF-EM), Hard rock environment, Groundwater development, Layer resistivity, Bed thickness mapping.

\begin{abstract}
In a hard rock environment with surface or near surface expression of outcrops, the use of VES only becomes difficult due to its associated problems and limitations. However, the use of VLF-EM becomes imperative in mapping basement structures relevant to groundwater development. A total of 2100 VLF-EM data plus selected VES points were covered over 7 traverses with length varying from 3000 to $4500 \mathrm{~m}$. The VLF-EM result mapped basement structures relevant in groundwater development. This is further studied using VES. Results of the investigation indicate that a HKH sounding curve is obtained with a maximum of five subsurface layers comprising: the top soil, clay/sandy clay unit, the fresh basement, fractured basement and the basement bedrock. The fractured basement layer constitutes the main aquifer unit with thickness of 20-25 $\mathrm{m}$. The layer resistivity and thickness ranges are 60-100 ohm-m; 40-80 ohm-m, 1600-2100 ohm-m, 250-420 ohm-m, and 2200-7500 ohm-m; and 0.3-1.2 $m, 1.9-2.5 \mathrm{~m}, 16.5-22.5 \mathrm{~m}$ and 22-30 $\mathrm{m}$ for the five layers respectively. The geoelectric results compared favorably well with drilling information to above $90 \%$. The yield of the well is $2 \mathrm{~L} / \mathrm{s}$ with good recharge capability.
\end{abstract}

\section{Introduction}

The Federal Housing Estate off Irese road, Akure is located on longitudes $5^{\circ} 11^{\prime} \mathrm{E}$ to $5^{\circ} 14^{\prime} \mathrm{E}$ and latitudes $7^{\circ} 17^{\prime} \mathrm{N}$ to $7^{\circ} 19^{\prime} \mathrm{N}$ (Figure 1). The area has not been connected to the municipal water supply system, thus the inhabitants rely solely on water from hand-dug wells, boreholes and at times streams. This area is characterized by surface manifestations of rocks that at times form high elevations. These surface expressions of these rocks have made groundwater abstraction difficult. Also, the presence of thin overburden in a hard rock terrain forced most of the hand-dug wells to terminate within the thin overburden thereby making wells in the area to be very shallow and seasonal.

In hard rock areas, groundwater is found in the cracks and fractures. Groundwater yield depends on the size of fractures and their interconnectivity. There- fore, in hard rock areas it is not sufficient to consider only the weathered layer, deep saturated fractures in bedrock are also potential targets of groundwater exploration. Geophysical methods are being routinely used for exploration of groundwater. Very Low Frequency electromagnetic (VLF-EM) has been applied successfully to map resistivity contrast at boundaries of fractured zones having a high degree of connectivity [Parasnis 1979]. It has been successfully applied to hydrogeological, engineering and environmental problems. Further, the VLF-EM method yields a higher depth of penetration in hard rock areas because of their high resistivity [McNeill and Labson 1991]. The advantage of VLF-EM is that it is relatively fast compared to many other geophysical methods. Hence, this method has probably been the most popular electromagnetic tool for quick mapping of near surface geologic structures in mineral exploration. However, it is being increasingly used for shallow groundwater exploration [Palacky et al. 1981] as a reconnaissance tool for weathered layer investigations. Also, VLF-EM has proved to be successful in identifying deep water bearing fractures in bedrock [Sundararajan et al. 2007].

The direct current (DC) resistivity method for conducting a vertical electrical sounding (VES) is effectively used for groundwater study due to the simplicity of the technique, easy interpretation and the rugged nature of the associated instrumentation. The technique is widely used in soft and hard rock areas [Ebraheem et al. 1997]. However, groundwater investigation in hard rock areas are often more difficult. It is very difficult to perform resistivity soundings everywhere without a-priori information. Therefore, a combined study of VLF and DC resistivity has potential to be successful [Bernard and Valla 1991, Benson et al. 1997, Sharma and Baranwal 2005]. 


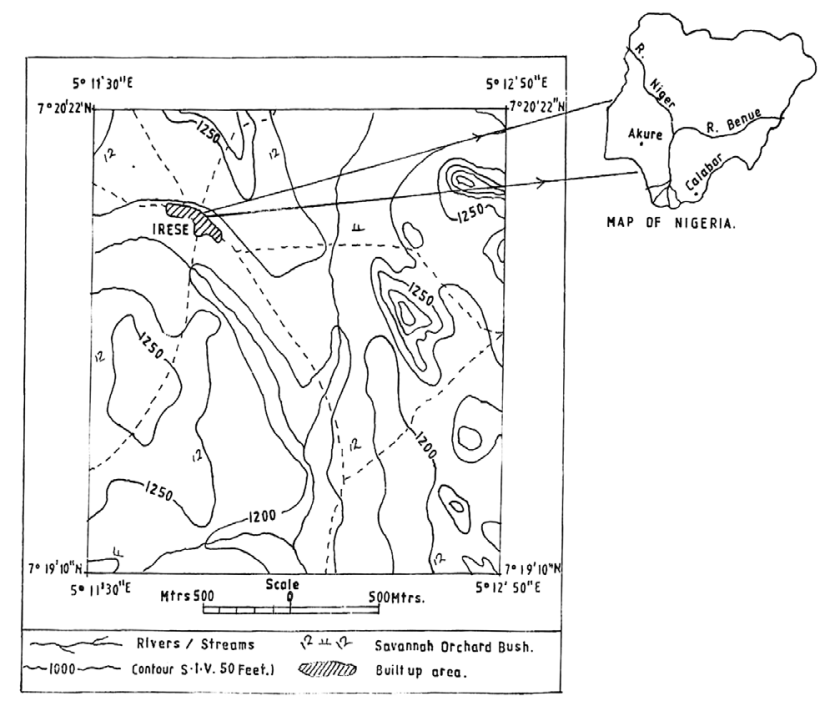

Figure 1. Topographical map of Irese area (Akure N.W. Sheet 264).

\section{Geology and hydrogeology}

Physiographically, the Federal housing estate in Akure metropolis southwestern Nigeria falls under the upland category and it shows a dendritic drainage pattern with a general flow towards the river course (Figure 1). The area is underlain by the Precambrian rocks typical of the Nigeria basement complex, which has been reviewed by workers like [Olarewaju 1987, Rahaman 1988].

The main rock types found in the area are charnockites, granite gneiss and porphyritic biotite granite (Figure 2a). This area is tectonically disturbed and the detection of water-bearing fracture systems at great depth levels is difficult.

Groundwater occurs at the study area within the thin overburden where poor-to-low yields that dry up during dry season, characterize hand-dug wells in the study area.

\section{Materials and method of study}

\subsection{Instrumentation}

VLF-EM is a passive method that uses the electromagnetic field generated by military navigation radio transmitters (there are about 42 global ground military communication transmitters) operating in the VLF frequency band $(15-30 \mathrm{KHz})$ as the primary electromagnetic field. These transmitters generate primary plane electromagnetic waves that can induce secondary eddy currents particularly in electrically conductive elongated (2D) targets. Although this range is very low for radio transmission, it is higher than that used in standard low frequency electromagnetic methods $(1-3 \mathrm{KHz})$.

Paal [1965] observed that radio waves at VLF could be used to prospect for conductive mineral deposits. Since then, VLF transmitters at several locations around the world have been used widely as EM sources for near surface geologic mapping. The VLF method was developed as an inductive survey technique to measure the amplitude and phase (dip angle/ ellipticity).

The VLF method is very sensitive to small changes in ground conductivity. The field radiated from a VLF transmitter over a uniform or horizontally layered earth consists of a vertical electrical field component and a horizontal magnetic field component, each perpendicular to the direction of the propagation [Sinha 1990].

The real part is the part of the resultant, which are inphase with the primary field from the VLF transmitter, while the imaginary part is the one that is $90^{\circ}$ out of phase with the primary field. The real and imaginary components consist the measurements recorded by the instrument.

\subsection{Geophysical investigation}

The objective of the geophysical study is to locate where drilling wells could be sited. Traverses were established in EW on longitudes $5^{\circ} 11^{\prime} \mathrm{E}$ to $5^{\circ} 12^{\prime} \mathrm{E}$ and latitudes $7^{\circ} 17^{\prime} \mathrm{N}$ to $7^{\circ} 18^{\prime} \mathrm{N}$. The geophysical investigations involved the Very Low Frequency Electromagnetic (VLF-EM) method and Vertical Electrical Sounding technique. The VLF-EM measurements were made at $10 \mathrm{~m}$ intervals along seven traverses (Figure $2 \mathrm{~b})$. The VLF traverses range in length from 3000-4500 $\mathrm{m}$ while the inter traverse distance is varied. The ABEM WADI VLF-EM receiver unit was used for the data collection. The transmitter used for this study is that of Great Britain (GBR) with frequency range of 15.2-15.6 $\mathrm{KHz}$. The direction of the transmitter $\left(\mathrm{T}_{\mathrm{X}}\right)$ is approximately parallel to the strike direction.

The instrument measures the tangent of the tilt angle (the inclination of the major axis of the polarization ellipse) and the ellipticity (the ratio of the minor to major axis of the ellipse) of the magnetic polarization ellipse. Both these quantities are affected by lateral variations in the subsurface conductivity. The tangent of the tilt angle $(\tan 2 \theta)$ and the ellipticity (e) are good approximations to the ratio of the real component of the vertical secondary magnetic field, and to the ratio of the quadrature component of the vertical secondary magnetic field to the horizontal primary field. These quantities are called the real $(=\tan \theta \times 100 \%)$ and imaginary $(=\mathrm{e} \times 100 \%)$ anomalies and are expressed in percent. For small secondary field strength, the two polarization parameters correspond to the real and imaginary components of the magnetic field and are expressed as ratios to the primary magnetic field. Thus, the measured tilt angle is called the real or inphase and the ellipticity is called imaginary (quadrature or out of phase) component. 
For the vertical electrical sounding (VES) the Schlumberger array has been used. The soundings were carried out only at locations where VLF-EM parameters suggested typical basement fractures. The current electrodes spacing $\mathrm{AB} / 2$ varied from $1.0 \mathrm{~m}$ to a maximum of $100 \mathrm{~m}$. The R50 DC Resistivity meter was used for the data collection.

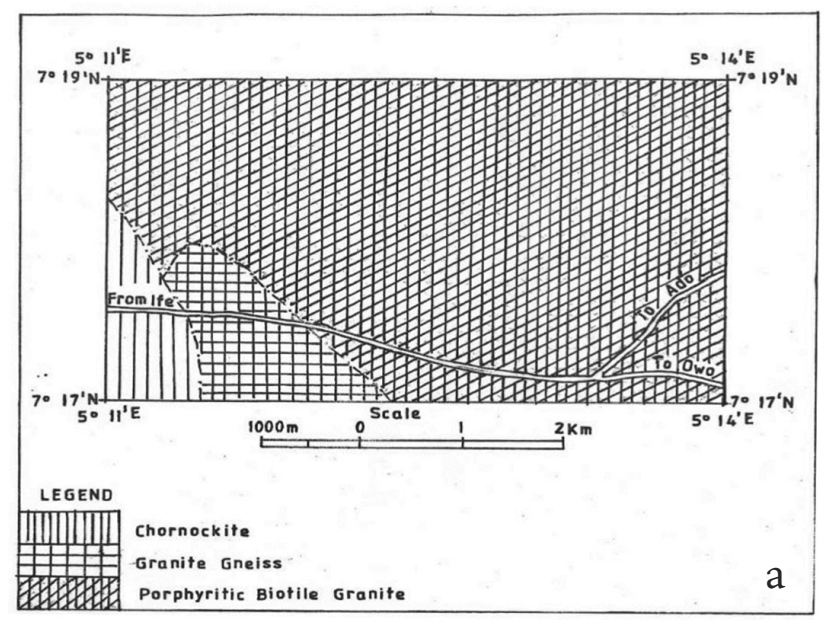

Figure 2 (above and below). (a) Geological map of Irese area Akure, SW Nigeria; (b) Geophysical data acquisition map.

\subsection{Filtering procedures}

The measured dip angle response needs to be filtered to reduce the random noise and long spatial wavelengths. However, for practical purposes it is not generally necessary to eliminate the noise, and long spatial wavelength as VLF ensures fairly accurate measurements with random errors well below an appreciable level. To overcome some of these problems, Fraser [1969] devised a simple numerical filter, which converts crossovers of current polarity into peaks by differencing successive values of tilt angle (the inphase component) along the profile. The Fraser filter shifts the measured dip angle data by $90^{\circ}$.

Thus, the Fraser filtering transforms the anomaly such that parts with maximum slope will appear as maximum amplitude. In a sequence of consecutive readings of tilt angle, say Q1, Q2, Q3 and Q4; the term (Q2 - Q1) not only shifts the dip angle but also attenuates the spatial wavelengths.

Numerically averaging weighted values of the adjacent sets of such differences i.e. $\left(\mathrm{Q}_{2}-\mathrm{Q}_{1}\right) / 4+\left(\mathrm{Q}_{3}-\right.$ $\left.\mathrm{Q}_{2}\right) / 2+\left(\mathrm{Q}_{4}-\mathrm{Q}_{3}\right) / 4$ which reduces to $\left(\mathrm{Q}_{3}+\mathrm{Q}_{4}\right)-$ $\left(\mathrm{Q}_{1}+\mathrm{Q}_{2}\right)$ reduces noise. Karous and Hjelt [1983] used linear filtering for the analysis of VLF dip angle data in an extension of the Fraser filter. They describe the mag-

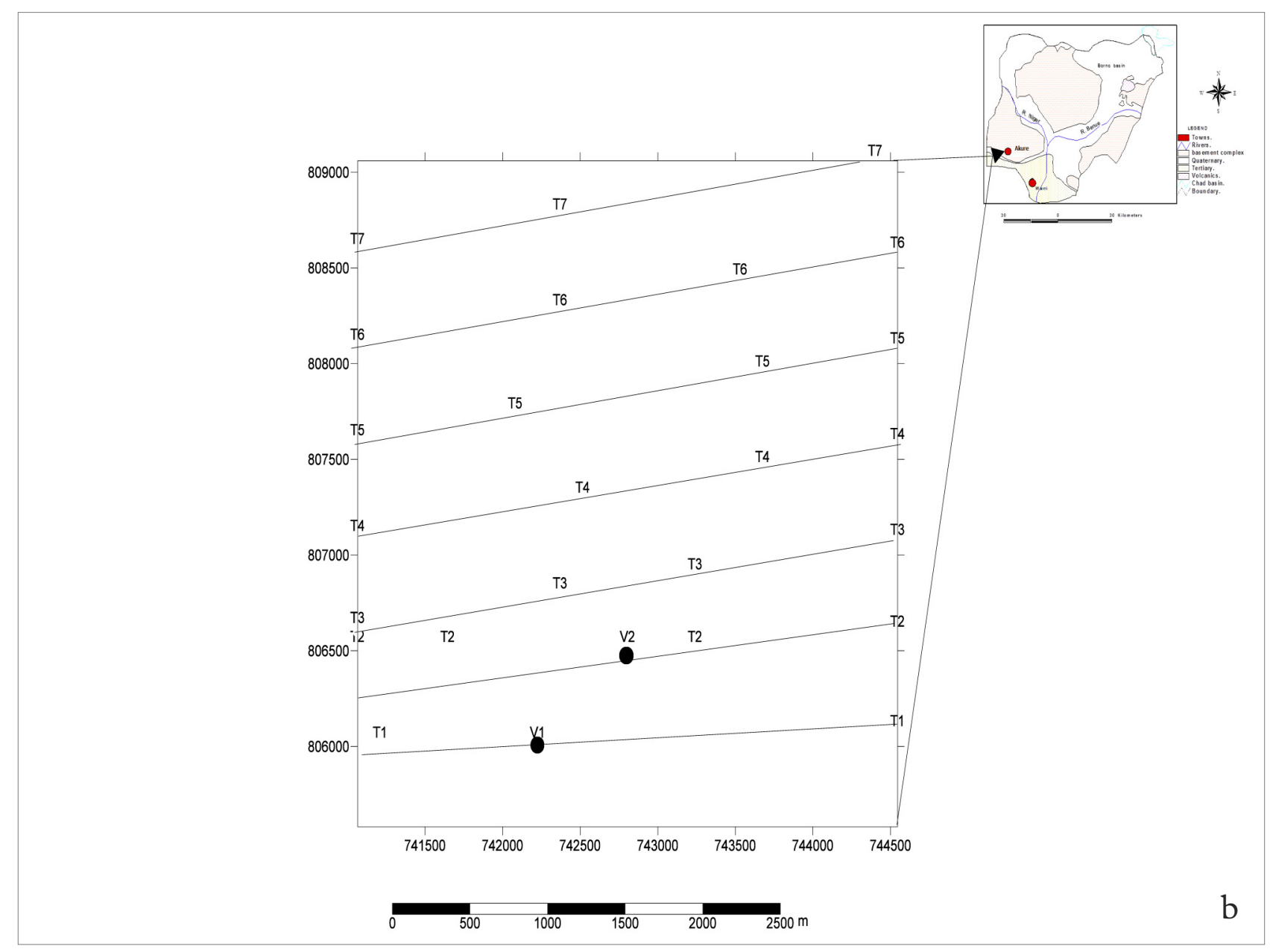


netic field arising from a subsurface $2 \mathrm{D}$ current distribution assumed in a horizontal sheet of varying current density situated everywhere at a depth equal to the distance between the measurement stations.

Their technique involves filtering the same data set for various depths and gives an idea about the change of current density with depth. Areas with high current density correspond to good conductors. This technique has found wide popularity as it provides a simple readily implemented scheme for semi quantitative analysis and target visualization. The apparent current density pseudosection should provide a pictorial indication of the depths of various concentrations and hence the spatial distribution of subsurface geologic features [Ogilvy and Lee 1991].

\subsection{Data interpretation}

The relationship between in phase and quadrature measurements may indicate the electrical conductivity of a water bearing fracture. Although it is known theo- retically that the conductor lies at the maximum of negative gradient (inflexion) of the VLF inphase component, however the crossover of the inphase and quadrature, plus the coincident inflection points of peak positive amplitude of the current density on the inphase are preferable as indicators of subsurface conductors.

Generally, VLF data are useful for obtaining qualitative view of the structure particularly after filtering and analyzing the sections. For reliable interpretation, VLF data alone are not enough, but can be used with the VES data to reduce non-uniqueness numerical values of resistivity and other VLF-EM parameters like Fraser derivative, current density (Hjelt filter).

From the VLF-EM profiles (Figure 3a-n) the distances are multiplied by a factor of 10 . The coincident inflection points on the positive peak of the filtered real and the Fraser peaks are diagnostic of fractures while the positive $\mathrm{KH}$ model is additional requirement of importance relevant in groundwater development
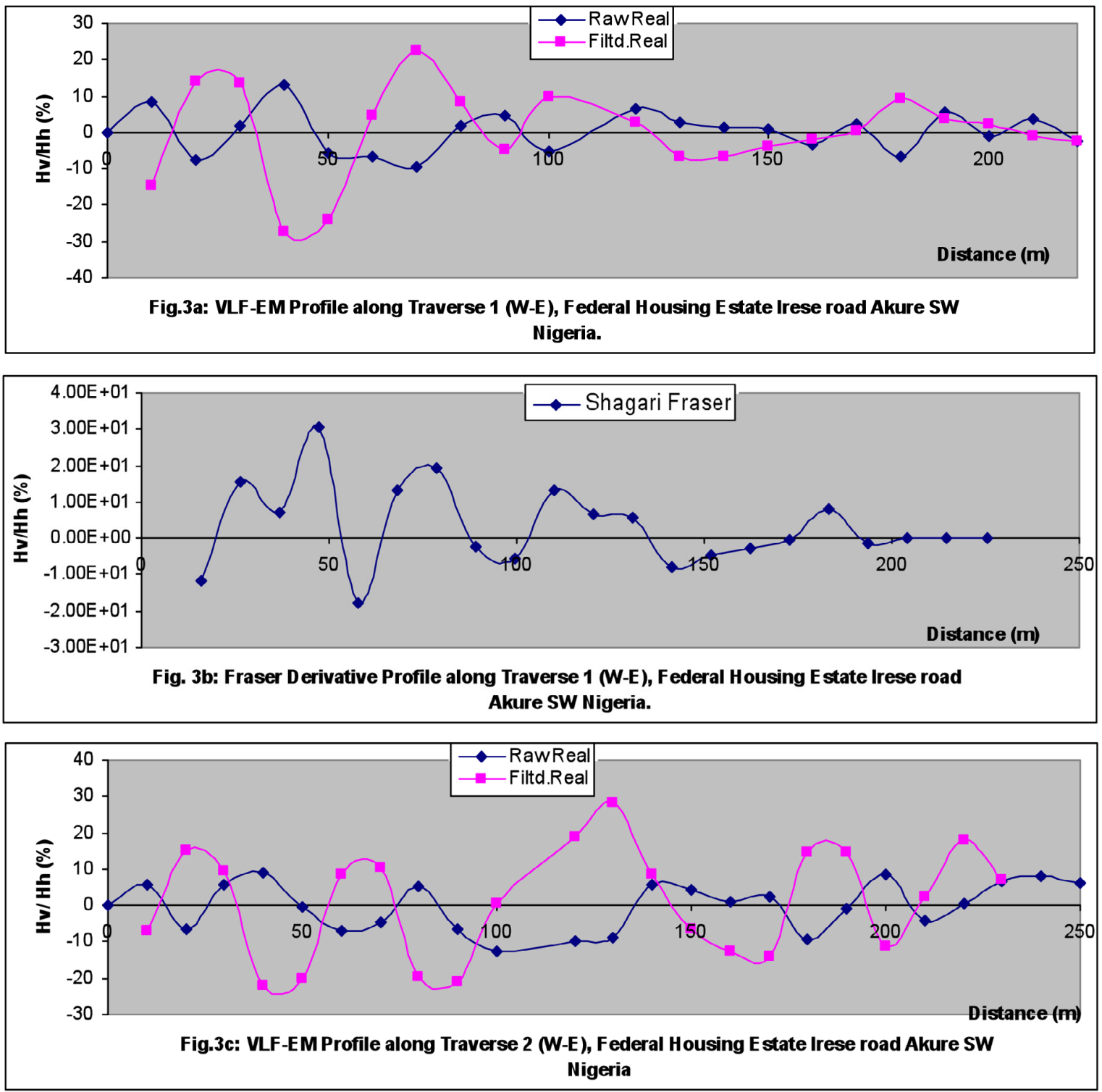

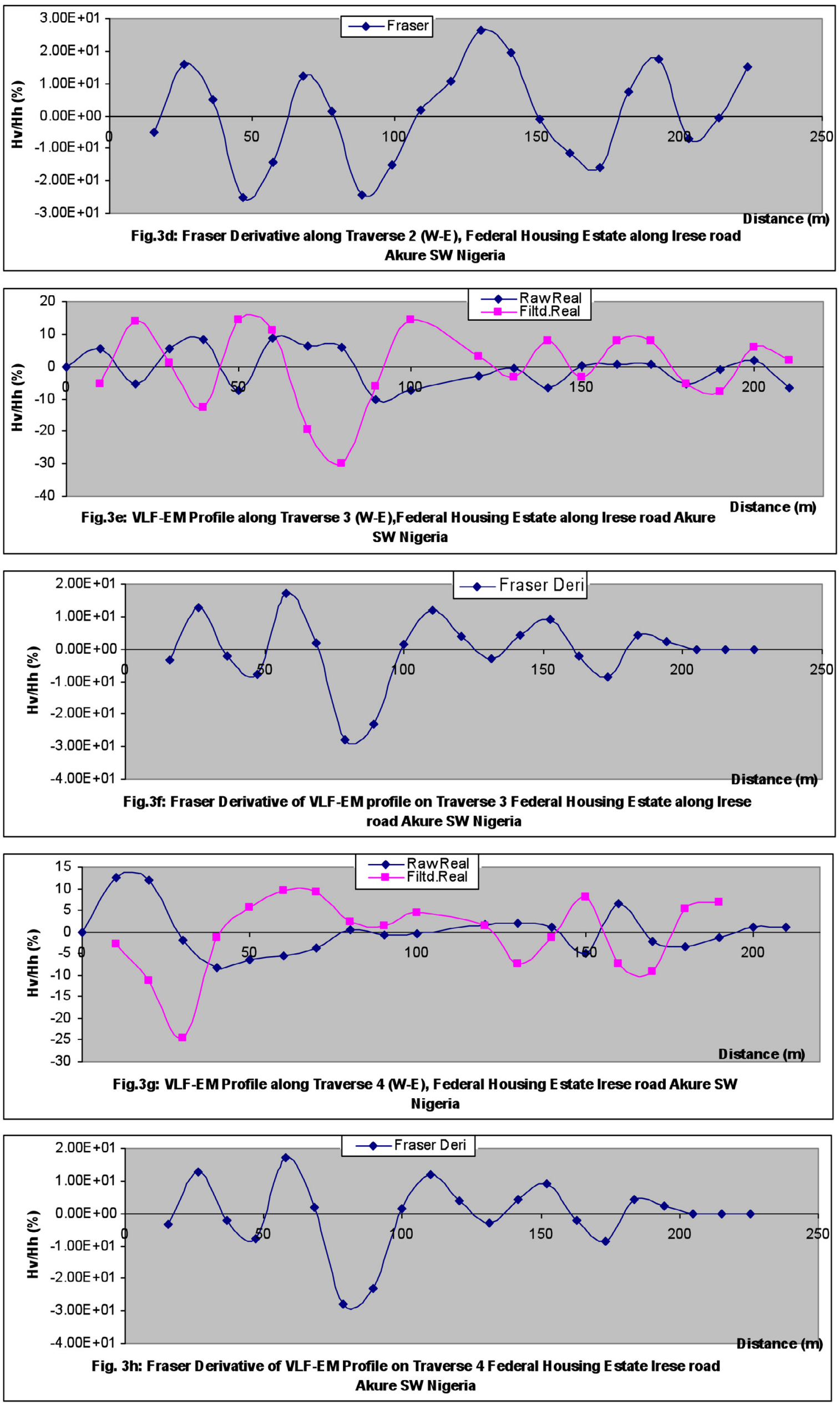

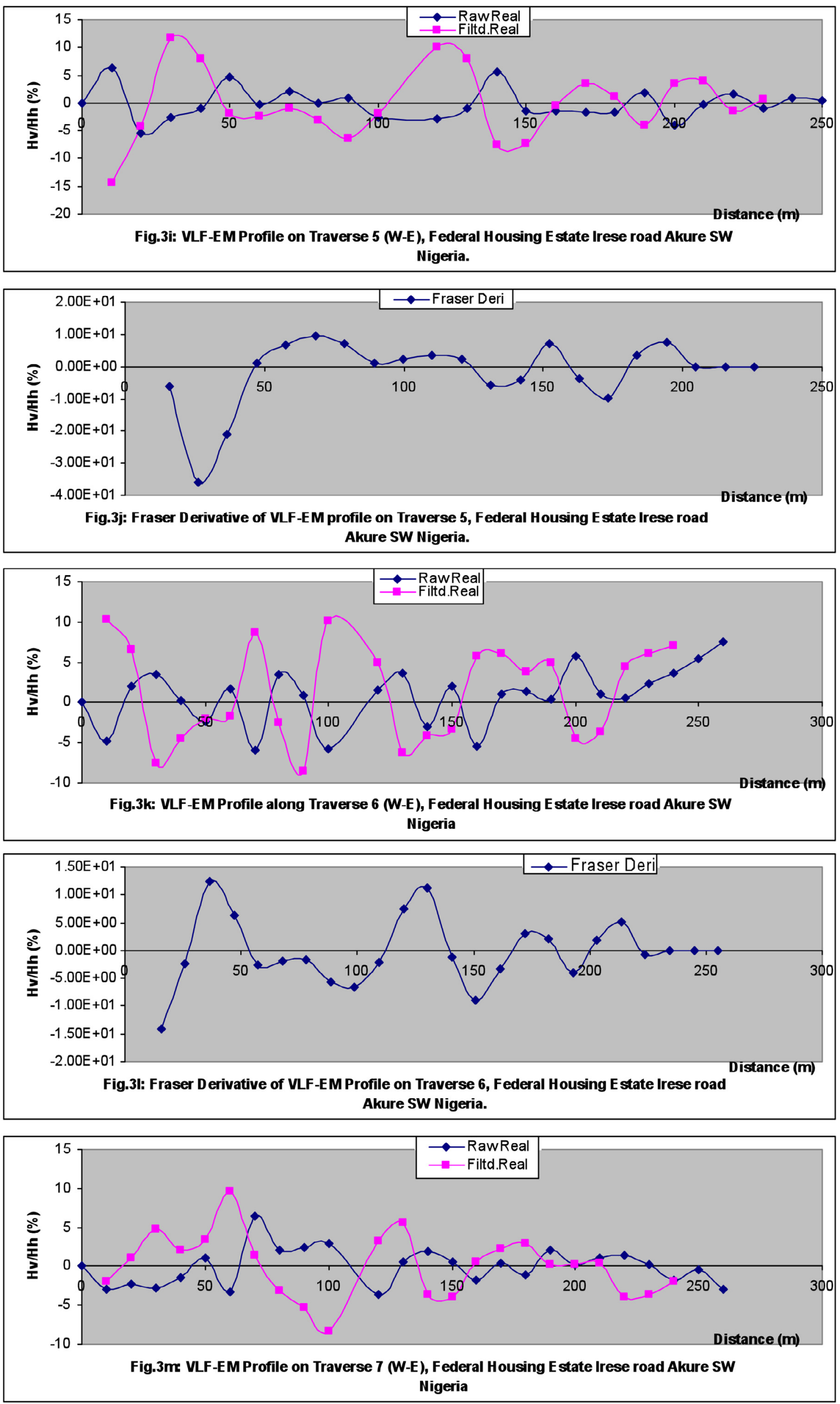

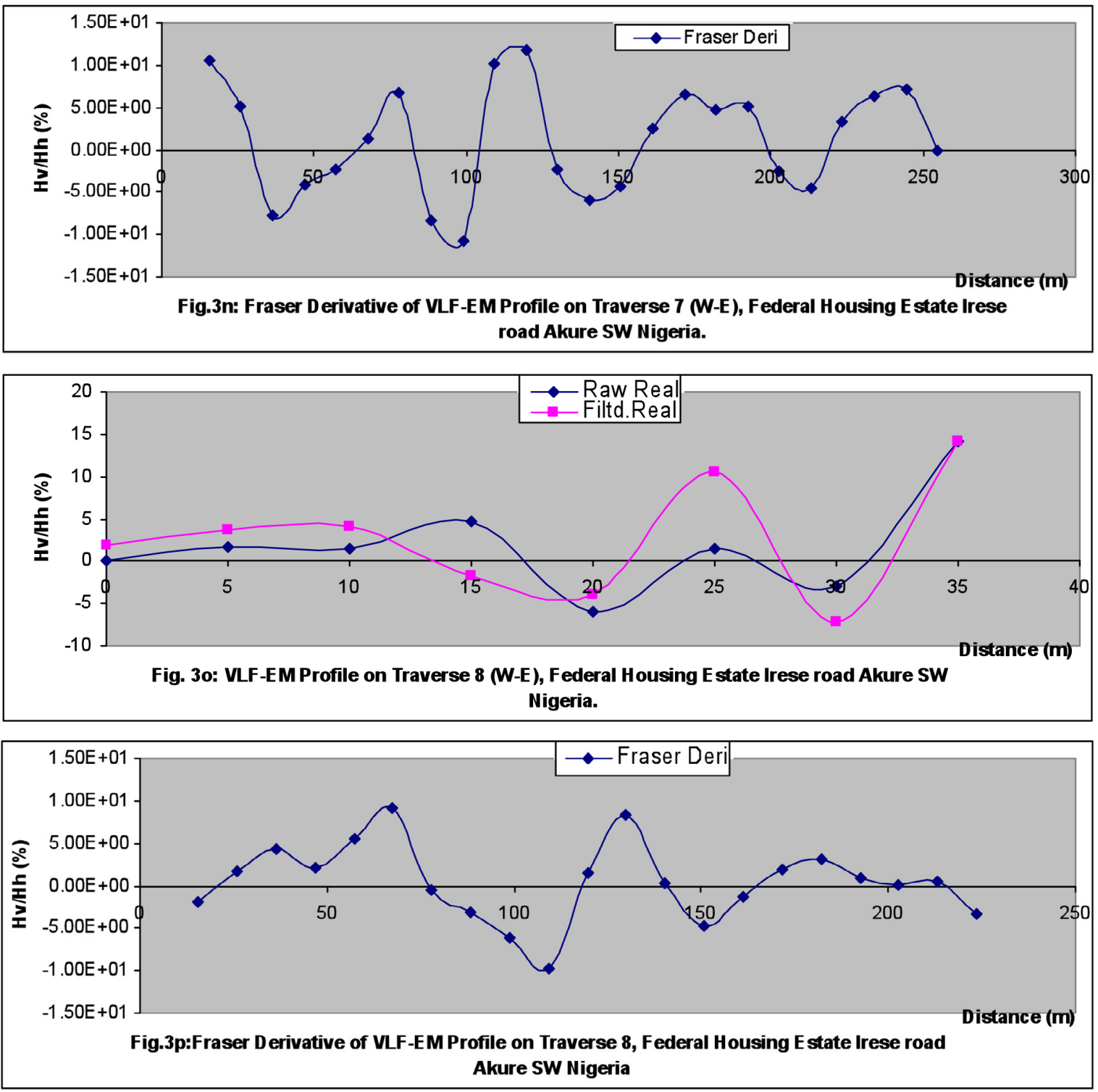

(Figure 4a-g). On the basis of these VLF-EM responses, series of conductors were identified $\left(\mathrm{C}_{1}-\mathrm{C}_{17}\right)$ as shown in Table 1.

Also, with further analysis and evaluation four fractures (f1-f4) were mapped, from which $\mathrm{f} 2$ and $\mathrm{f} 4$ (70 m on Traverse 1 and $120 \mathrm{~m}$ on Traverse 2) were marked for further investigation as sites 1 and 2 respectively (Table 1 ) due to their attitude, length of the fractures and depth extent $(>30 \mathrm{~m})$. Thus, a follow-up study of the two sites using Vertical Electrical Sounding (VES) technique employing Schlumberger configuration was used.

The VES curves were interpreted quantitatively using partial curve matching technique. The initial parameters for the models (Figure $5 \mathrm{a}$ ) of sites I and II were obtained from the traditional method using master curves and auxiliary charts [Orellana and Mooney 1966]. The results were refined using computer iteration technique; DC Inversion and Resist geophysical software packages were used to generate layer resistivity and thickness (Figure 5a,b,c). Figure 6 is the map showing the positions of the fractures as obtained and delineated from the VLF-EM responses on the profiles. A total of five (5) major basement fractures were delineated relevant in groundwater prospecting. Also, the VES locations are situated on the identified fracture points.

\section{Results and discussion}

In this study, at $700 \mathrm{~m}$ on $\mathrm{T}_{1}$ correspond to $\mathrm{V} 1$ (site 1), the analysis of the VES responses (Figure 5ac) revealed a HKH curve type $\left(\rho_{1}>\rho_{2}<\rho_{3}>\rho_{4}<\rho_{5}\right)$, five-layered geoelectric structure with high-resistivity substratum $(>2100 \Omega \mathrm{m})$. The weathered layer is of thickness $2.2-3 \mathrm{~m}$ corresponding to resistivity of the order of 40-100 $\Omega \mathrm{m}$ ). The existence of a high resistive basement rock (1830-2500 $\Omega \mathrm{m}$ ) with thickness of 15.8$18.5 \mathrm{~m}$ ) underlain the weathered layer at shallow depth, indicated that VLF-EM and VES would be appropriate techniques to explore the possibility of delineating water bearing fractures where significant 

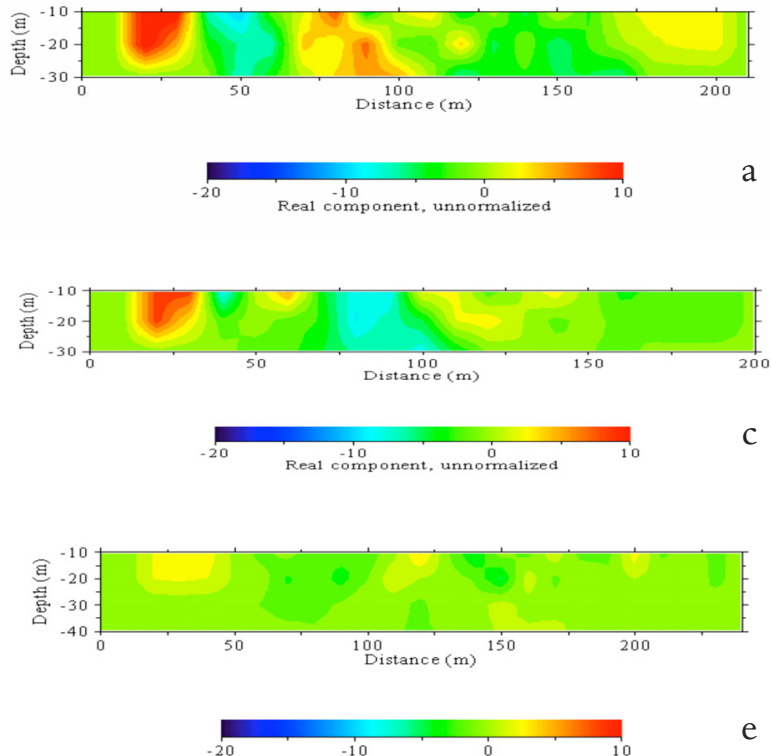

Real component, unnormalized

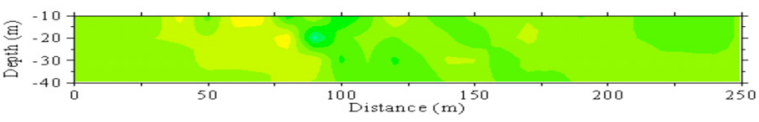

Real component, $\begin{gathered}-10 \\ \text { in } \\ \text { unnolized }\end{gathered}$
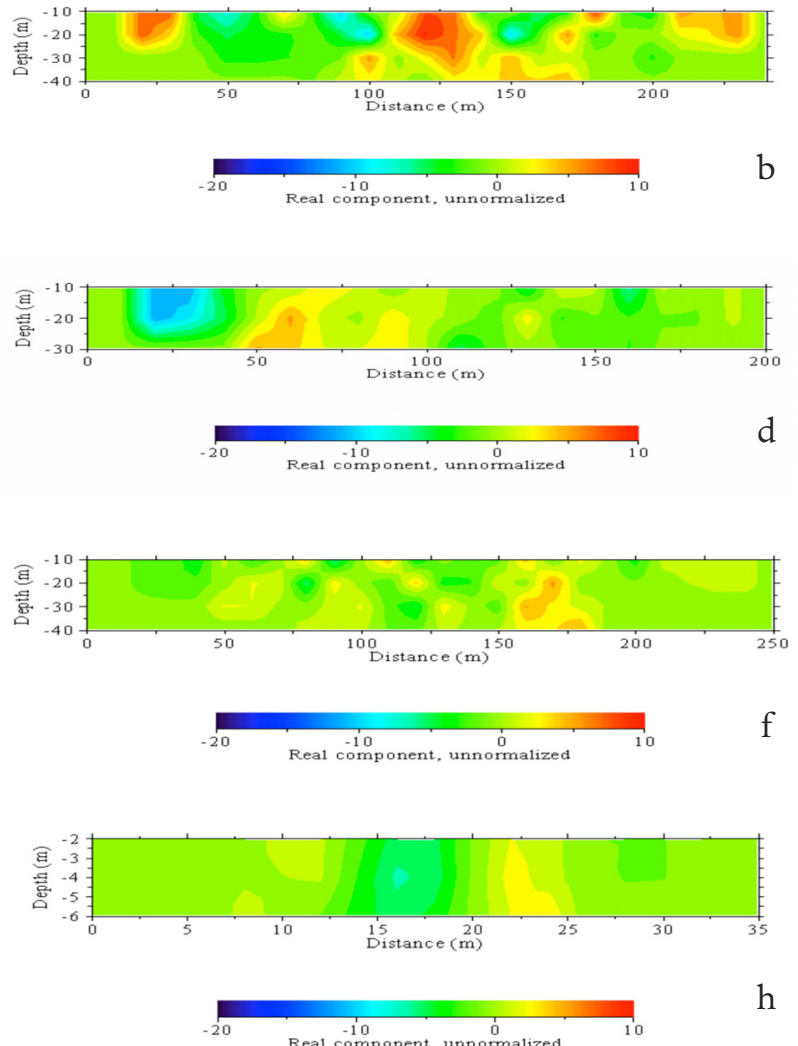

$\mathrm{h}$

Figure 4. Numerical modeling (KH model) of the inphase component of very low frequency electromagnetic method (VLF-EM) on Federal Housing Estate Irese, Nigeria: (a) Traverse 1, (b) Traverse 2, (c) Traverse 3, (d) Traverse 4, (e) Traverse 5, (f) Traverse 6, (g) Traverse 7, (h) Traverse 8.

\begin{tabular}{|c|c|c|c|c|c|c|c|c|}
\hline $\begin{array}{c}\text { Traverse } \\
\text { no. }\end{array}$ & $\begin{array}{l}\text { Distance } \\
(\mathrm{m}) \times 10\end{array}$ & $\begin{array}{l}\text { Coincident } \\
\text { inflection } \\
\text { points }\end{array}$ & Conductors & $\begin{array}{c}\text { Fraser } \\
\text { derivative }\end{array}$ & $\begin{array}{c}\mathrm{KH} \\
\text { section }\end{array}$ & $\begin{array}{l}\text { Geologic } \\
\text { structure }\end{array}$ & Attitude & Remark \\
\hline T1 & 30 & Yes & $\mathrm{C} 1$ & +ve peak & Positive & F1 & Shallow depth & \\
\hline T1 & 70 & Yes & $\mathrm{C} 2$ & +ve peak & Positive & F2 & $\begin{array}{c}\text { Dipping, } \\
\text { deeper depth }\end{array}$ & Site 1 \\
\hline $\mathrm{T} 1$ & 110 & Yes & C3 & +ve peak & Positive & F3 & Shallow depth & \\
\hline $\mathrm{T} 2$ & 70 & Yes & $\mathrm{C} 4$ & +ve peak & Negative & & & \\
\hline $\mathrm{T} 2$ & 120 & Yes & C5 & +ve peak & Positive & F4 & $\begin{array}{c}\text { Dipping, } \\
\text { deeper depth }\end{array}$ & Site 2 \\
\hline $\mathrm{T} 2$ & 190 & Yes & C6 & +ve peak & Negative & & & \\
\hline T3 & 100 & Yes & $\mathrm{C} 7$ & - & & & & \\
\hline T3 & 165 & Yes & $\mathrm{C} 8$ & -ve peak & Negative & & & \\
\hline $\mathrm{T} 4$ & 65 & Yes & $\mathrm{C} 9$ & - & Positive & & & \\
\hline $\mathrm{T} 4$ & 100 & Yes & $\mathrm{C} 10$ & - & Negative & & & \\
\hline T5 & 30 & Yes & C11 & - & Negative & & & \\
\hline T5 & 115 & Yes & $\mathrm{C} 12$ & +ve peak & Negative & & & \\
\hline T5 & 170 & Yes & $\mathrm{C} 13$ & -ve peak & Negative & & & \\
\hline T5 & 210 & Yes & C14 & -ve peak & Negative & & & \\
\hline T6 & 160 & Yes & $\mathrm{C} 15$ & -ve peak & Positive & & & \\
\hline T7 & 120 & Yes & $\mathrm{C} 16$ & +ve peak & Negative & & & \\
\hline T7 & 180 & Yes & $\mathrm{C} 17$ & +ve peak & Negative & & & \\
\hline T8 & 25 & Yes & $\mathrm{C} 18$ & +ve peak & Positive & F5 & & \\
\hline
\end{tabular}

Table 1. VLF-EM interpreted results. 
resistivity contrast exist. The fourth geoelectric layer corresponds to the fractured basement with thickness of (22.5-28.9 m) and resistivity of 330-420 $\Omega \mathrm{m}$. The corresponding 1-D geoelectric section and the drilling results of this site are shown in Figure $7 \mathrm{a}$ and $\mathrm{b}$, respectively. Drilling has confirmed water at a depth of 18.1-39.3 $\mathrm{m}$ with a yield of $2 \mathrm{~L} / \mathrm{s}$ and the overall depth of hole is about $40 \mathrm{~m}$. The interpreted depths of 17.2$39.6 \mathrm{~m}$ of fractured basement coincide with the depth at which water was struck at $18.1-39.3 \mathrm{~m}$ implying an error approximate of less than $2 \%$ between interpreted drilling depths.

Also, at $1200 \mathrm{~m}$ on T2, the VES 2 was measured. In this case, the loose weathered materials thickness range from 2.5 to $4.5 \mathrm{~m}$. Solid basement $(7.3-9.1 \mathrm{~m}$ thick) was found below the weathered loose materials, thus the thickness of materials above the aquifer zone is $10.1-11.1 \mathrm{~m}$ while the fractured/weathered basement layer is mostly $25.5-29.5 \mathrm{~m}$ thick in the choice lo-

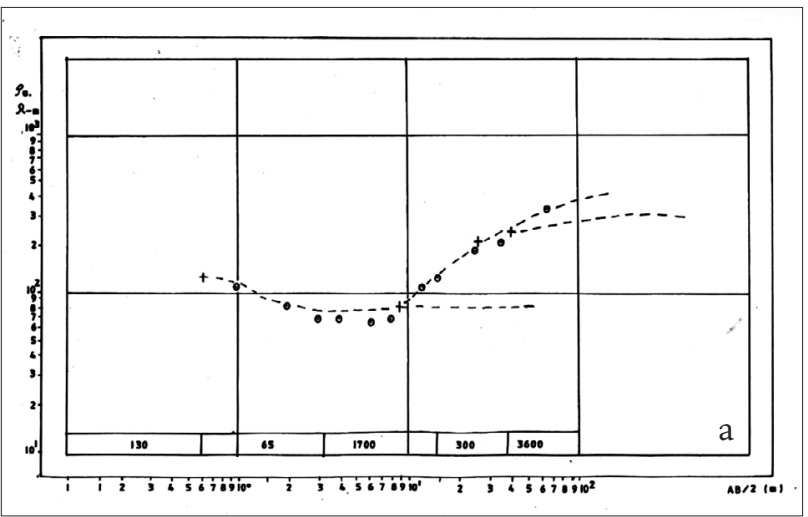

cation (VES2). Resistivity parameters suggest medium groundwater saturation in the hydrogeologic units of this location.

\section{Conclusion}

The VLF-EM measurements were employed on an experimental basis for qualitative assessments of water bearing fractures and thereby to find optimum loca-

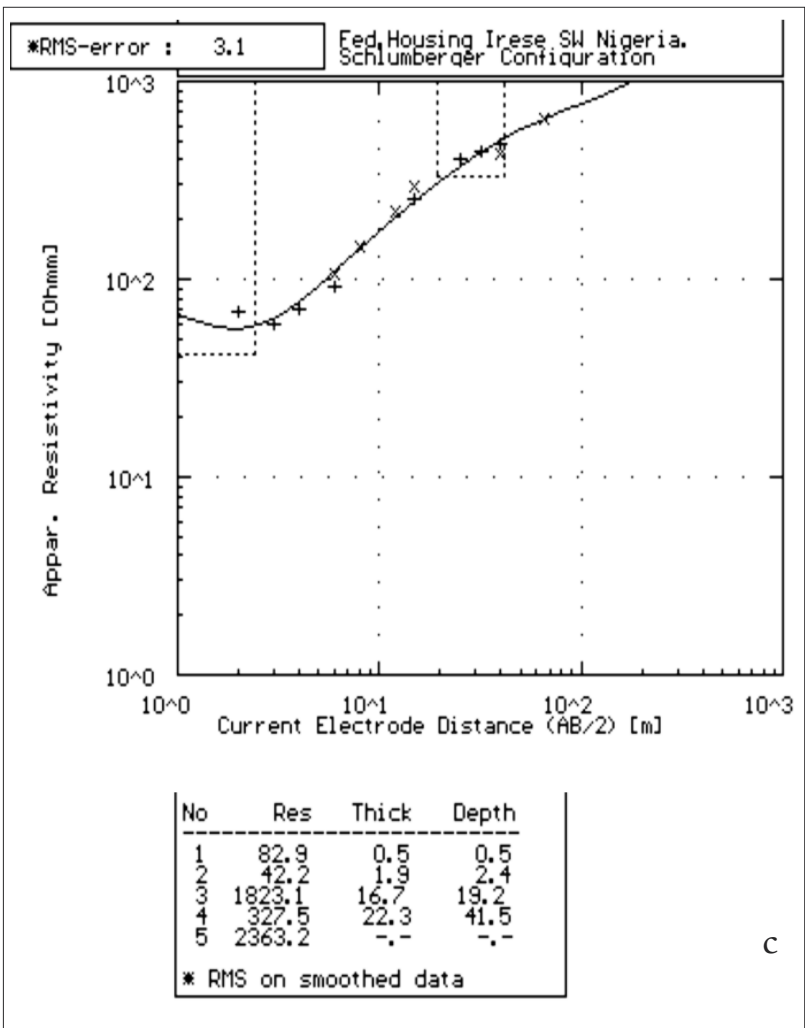

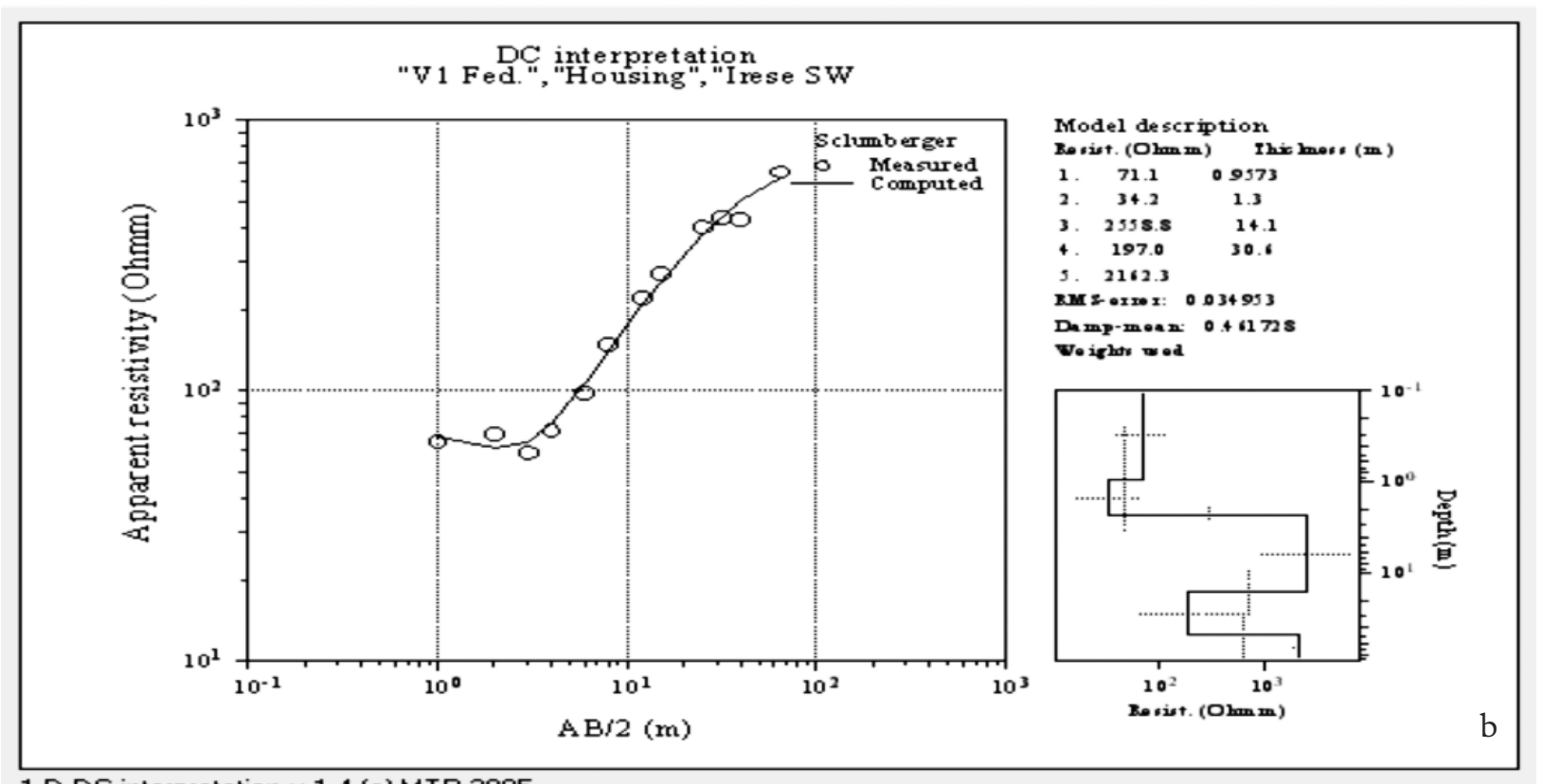

1-D DC interpretation $\vee .1 .4$ [c] MTP 2005

Figure 5. Manual and iterated VES curve at V1 in Irese area, Akure, SW Nigeria. 


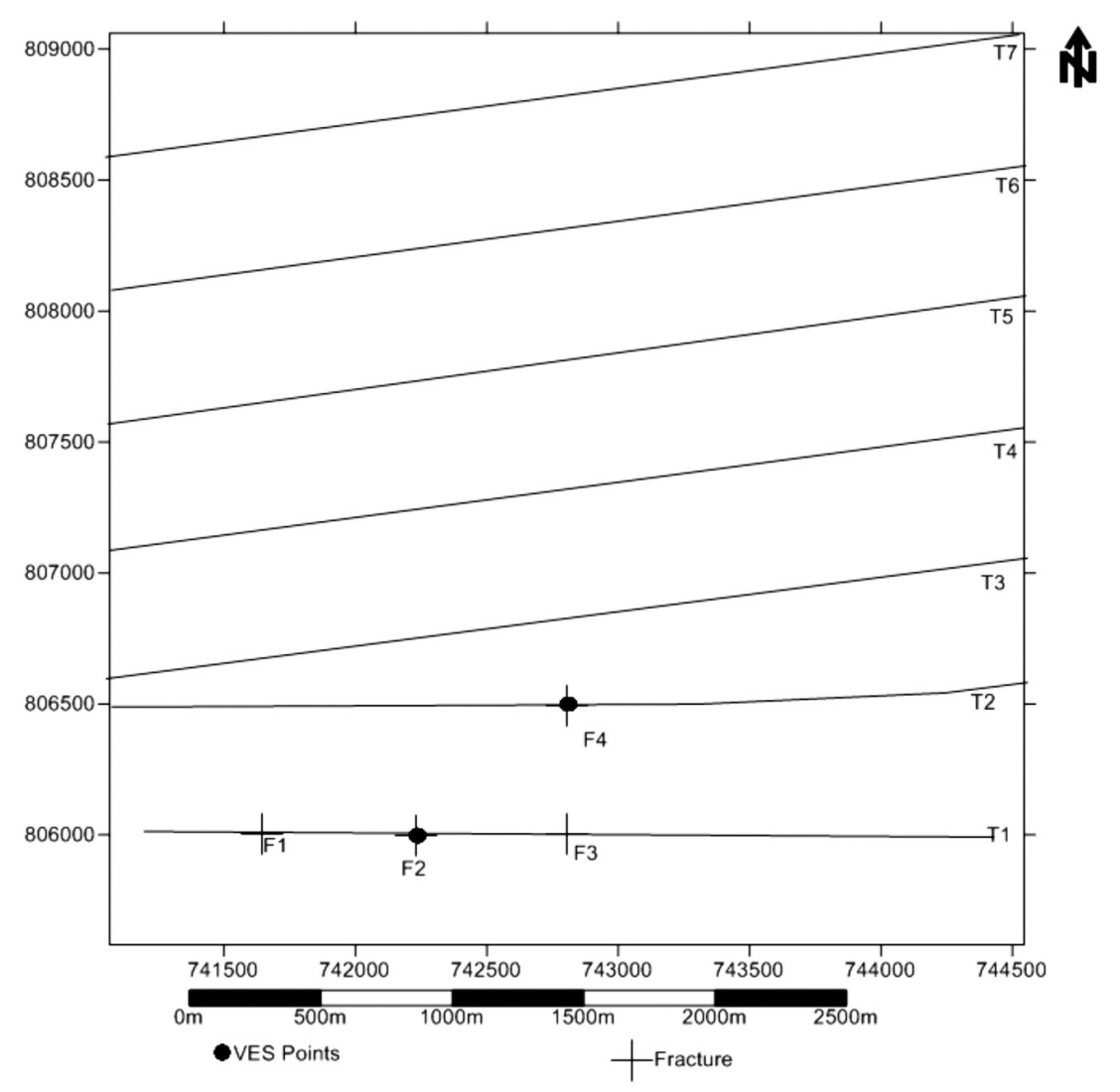

Figure 6. Geophysical data acquisition map showing fracture points.

tions to drill for groundwater. The appropriate coincident inflection points of the raw real and filtered real parts, the inphase and quadrature (out of phase) components of the VLF measured on the field, the positive peaks of the Fraser derivative of the inphase component coupled with positive current density pseudosection using the Hjelt filter determine the points to be selected for drilling with VES results. The depths obtained from the combined VLF/VES results agree with the depth at which water was struck.

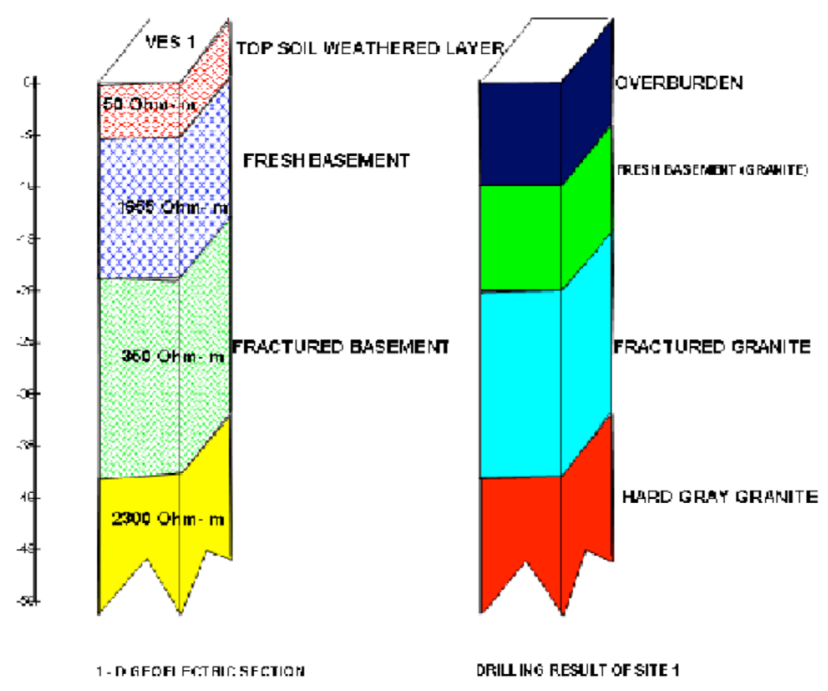

Figure 7. 1-D geoelectric section and drilling result in site 1.

\section{References}

Benson, A.K., K.L. Payne and M.A. Stubben (1997). Mapping groundwater contamination using DC resistivity and VLF geophysical methods - A case study, Geophysics, 62, 80-86.

Bernad, J., and P. Valla (1991). Groundwater exploration in fissured media with electrical and VLF methods, Geoexploration, 27, 81-91.

Ebraheem, A.M., M.M. Sensory and K.A. Dahab (1997). Geoelectrical and Hydrochemical studies for delineating groundwater contamination due to salt water intrusion in the northern part of the Nile delta, Egypt, Groundwater, 35, 216-222.

Fraser, D.C. (1969). Contouring of VLF-EM data, Geophysics, 34, 958-967.

Kaikkonen, P. (1979). Numerical VLF modeling, Geophysical Prospecting, 27, 815-834.

Karous, M., and S.E. Hjelt (1983). Linear filtering of VLF dip angle measurements, Geophysical Prospecting, 31, 782-894.

McNeill, J.D., and V.F. Labson (1991). Geological mapping using VLF Radiofields, In: M.N. Nabighian (ed.), Geotechnical and Environmental Geophysics, vol. 1: Review and Tutorial, Society of Exploration Geophysicists, Tulsa, 191-218.

Ogilvy, R.D., and A.C. Lee (1991). Interpretation of VLF-EM inphase data using current density pseudosections, Geophysical Prospecting, 39, 567-580. 
Olarewaju, V.O. (1987). Charnokitic - Granite association in SW Nigeria: Rapakiwi granite type and charnokitic Platonism in Nigeria, Journal of African Earth Science, 6 (1), 67-77.

Orellana, E., and H. Mooney (1966). Master Tables and Curves for Vertical Electrical Sounding over Layered Structures, Interciencia, Madrid, $125 \mathrm{pp}$.

Paal, G. (1965). Ore prospecting based on VLF-radio signals, Geoexploration, 3, 139-147.

Palacky, G.J., I.L. Ritsema and S.J. de Jong (1981). Electromagnetic prospection for groundwater in Precambrian terrains in the Republic of Upper Volta, Geophysical Prospecting, 29, 932-955.

Parasnis, D.S. (1979). Principles of Applied Geophysics, 3rd ed., Chapman and Hall, New York, 269 pp.

Rahaman, M.A. (1988). Recent advances in the study of the basement complex of Nigeria, In: Precambrian geology of Nigeria, Geological survey of Nigeria, Kaduna south, 11-43.

Sharma, S.P., and V.C. Baranwal (2005). Delineation of groundwater bearing fracture zones in a hardrock area integrating Very Low Frequency Electromagnetic and Resistivity data, Journal of Applied Geophysics, 57, 155-166.

Sinha, A.K. (1990). Interpretation of ground VLF-EM data in terms of vertical conductor models, Geoexploration, 26, 213-231.

Sundararajan, N., G. Nandakumar, M. Narsimha and Y. Srinivas (2007). VES and VLF - an application to groundwater exploration, Khammam, India, The Leading Edge, 26 (6), 708-716.

${ }^{\star}$ Corresponding author: John Stephen Kayode,

Covenant University, Department of Physics, Canaan Land, Otta, Nigeria; email: jskayode@gmail.com.

(C) 2014 by the Istituto Nazionale di Geofisica e Vulcanologia. All rights reserved. 